\title{
SISTEM INFORMASI MONITORING PERJALANAN KAPAL BERBASIS WEB PADA PT. PELAYARAN LAUT SERAYA
}

\author{
${ }^{1}$ Siti Monalisa , ${ }^{2}$ Ade Indra Sukma \\ ${ }^{1,2,3}$ Program Studi Sistem Informasi, Fakultas Sains dan Teknologi UIN Suska Riau \\ J1. HR Soebrantas KM.18 Panam Pekanbaru - Riau \\ Email: ${ }^{1}$ siti.monalisa@uin-suska.ac.id, ${ }^{2}$ adeindrasukma@gmail.com,
}

\begin{abstract}
ABSTRAK
PT. Pelayaran Laut Seraya didirikan pada tahun 1987 beralamat di jalan Diponegoro No. 18 Kelurahan Selatpanjang Kota Kecamatan Tebing Tinggi Kabupaten Kepulauan Meranti Provinsi Riau, PT. Pelayaran Laut Seraya memiliki kantor cabang di kota Pekanbaru yang beralamat dijalan Bintara No. 14G Kelurahan Kota Tinggi Kec. Pekanbaru Kota. PT. Pelayaran Laut Seraya memiliki berbagai macam aktifias seperti memberi jadwal keberangkatan kapal, memonitoring pergerakan kapal, membuat aset dokumen kapal. Penggunaan sistem yang sedang berjalan saat ini membutuhkan banyak kertas sebagai bahan untuk pencetakkan file yang telah dimasukkan, dan dengan proses yang lama juga membutuhkan banyak waktu yang akan membuat pekerjaan semakin menumpuk, dalam sistem ini juga membuat pencarian data dari waktu ke waktu semakin sulit dicari karena data yang ada saat ini sudah sangat banyak, dan data tersebut di simpan sheet per sheet di dalam microsoft excel. Tujuan dari penelitian ini adalah untuk membangun sistem mengenai data kapal dan memonitoring perjalanan kapal untuk PT.Pelayaran Laut Seraya. Sistem yang dibangun merupakan sistem yang dapat membantu PT.Pelayaran Laut Seraya dalam menjalankan proses bisnisnya, diantaranya seperti memonitoring data perjalanan kapal, penginputan dan pengolahan data kapal, membuat laporan perjalanan kapal, memonitoring surat-surat kapal. Teknik perancangan sistem menggunakan metode Object Oriented Analysis Design (OOAD) dan Tools Unified Modelling Language (UML), Teknik testing sistem menggunakan metode Blackbox dan User Acceptance Test (UAT) dengan metode pengembangan sistem menggunakan metode waterfall yang merupakan metode dengan model sekuensial. Hasil penelitian ini adalah sebuah sistem informasi monitoring perjalan kapal berbasis web.
\end{abstract}

Kata kunci: blackbox, UAT, monitoring, OOAD, UML, waterfall.

\section{A. PENDAHULUAN}

Dalam perkembangan dunia bisnis sekarang, baik perusahaan yang baru memulai untuk bersaing maupun yang telah berkembang jauh, mulai menyadari pentingnya teknologi informasi baik itu dalam mengembangkan usahanya semakin jauh kedepan agar tidak tertinggal jauh oleh para pesaing maupun dalam memaksimalkan keuntungan yang didapatkan. Pemanfaatan teknologi yang mutakhir berguna untuk menggantikan kerja manusia serta berguna untuk perkembangan ilmu pengetahuan dan menjadi sarana dan prasarana oleh perusahaan yang telah berkembang.

Perkembangan teknologi informasi yang berdampak paling besar dirasakan dalam kehidupan salah satunya ialah kegiatan bertukar data secara cepat dengan pemanfaatan teknologi informasi sebagai medianya. Pengolahan data maupun informasi yang semakin banyak sudah tidak efektif lagi dilakukan dengan menggunakan metode manual. Maka dibutuhkan suatu alat yang memiliki tingkat keakuratan dan kecepatan perhitungan dan penyampaian informasi dalam pengelolaan perjalanan kapal. Salah satunya yaitu pengelolaan perjalanan kapal, pengelolaan data perjalanan kapal pada PT. Laut Seraya Tbk.

PT. Pelayaran Laut Seraya didirikan pada tahun 1987 beralamat di jalan Diponegoro No. 18
Kelurahan Selatpanjang Kota Kecamatan Tebing Tinggi Kabupaten Kepulauan Meranti Provinsi Riau. PT. Pelayaran Laut Seraya pada saat ini dipimpin oleh bapak Roslan Oei selaku Direktur Utama, PT. Pelayaran Laut Seraya memiliki kantor cabang di kota Pekanbaru yang beralamat dijalan Bintara no $14 \mathrm{G}$ Kelurahan Kota Tinggi Kec. Pekanbaru Kota, PT. Pelayaran Laut seraya adalah Perseroan yang bergerak dalam bidang jasa pelayaran juga menyediakan jasa angkutan laut, menjadi agen perantara dan pencari muatan, penyewaan kapal, dan jasa penunjang angkutan laut lainnya. Dalam Jasa Pelayaran, Perseroan menyediakan Jasa Penyewaan kapal. PT. Pelayaran Laut Seraya memiliki 14 armada kapal dengan jenis Tugboat dan 14 armada kapal Tongkang / Barge yang saat ini aktif dalam kegiatan jasa angkutan laut khususnya bahan - bahan produksi perusahaan pengguna jasa angkutan.

Sebagai perusahaan yang bergerak dibidang angkutan PT. Pelayaran Laut Seraya memiliki berbagai macam aktifitas seperti memberi jadwal keberangkatan kapal, memonitoring pergerakan kapal, membuat aset dokumen kapal. Kegiatan yang dilakukan pada PT. Pelayaran Laut Seraya yaitu melakukan kegiatan monitoring yang dilakukan setiap hari oleh bagian operasional dengan menelpon setiap kapten kapal yang berjumlah 14 
kaptel kapal untuk menanyakan keadaan atau situasi kapal, yang kemudian bagian operasional memasukkan data yang di dapat ke dalam microsoft excel yang kemudian di cetak untuk dilaporkan kepada direktur utama, yang berada dilantai dua, setelah laporan diketahui oleh direktur utama bagian operasional memindai (scan), hasil scan tadi dikirim ke mitra kerja serta pemilik saham melalui $e$-mail, kemudian laporan tadi diserahkan oleh bagian pengarsipan untuk dapat di arsipkan, serta diserahkan bagian keuangan untuk dapat melihat laporan tersebut.Setiap hari bagian operasional selalu memonitoring kegiatan kapal-kapal yang dimiliki oleh PT. Pelayaran Laut Seraya baik kapal tersebut sedang dalam perjalanan ataupun dalam perbaikan.

Penggunaan sistem yang sedang berjalan saat ini membutuhkan banyak kertas sebagai bahan untuk pencetakkan file yang telah diinputkan, dan dengan proses yang lama juga membutuhkan banyak waktu yang akan membuat pekerjaan semakin menumpuk, dalam sistem ini juga membuat pencarian data dari waktu ke waktu semakin sulit di cari karena data yang ada saat ini sudah sangat banyak, dan data tersebut di simpan sheet per sheet dalam microsoft excel.

Dengan adanya sistem informasi monitoring berbasis web nantinya diharapkan membuat pekerjaan para karyawan di PT. Pelayaran Laut Seraya lebih efektif dalam segi waktu dan biaya, juga akan lebih mudah dalam penginputan data dan pencarian data yang telah lama, dan dengan adanya sistem informasi berbasis web ini diharapkan akan lebih memaksimalkan pekerjaan setiap karyawan.

\section{B. LANDASAN TEORI}

\section{B.1. Konsep Dasar Monitoring}

Menurut Tery yang ditulis oleh Risnandar dkk. (2015), monitoring bermakna memastikan apa yang telah dikerjakan, hal ini bermaksud menilai kembali prestasi kerja dan apabila dibutuhkan, mempraktikkan tindakan-tindakan korektif sehingga hasil pekerjaan sesuai dengan rencana yang telah ditetapkan. Aktivitas pengawasan atau monitoring ini bermaksud agar dapat memahami keserupaan dan kegiatan yang dilakukan sudah dikerjakn secara tepat sesuai dengan apa yang telah direncanakan. Hal ini juga bermanfaat untuk membenahi tindakantindakan yang tidak sesuai dengan planning yang telah dipersiapkan.

\section{B.2. Object Oriented Analysis and Design (OOAD)}

Object oriented analysis adalah suatu metode analisa yang berfungsi untuk memeriksa keperluan yang harus dipenuhi suatu sistem dari sudut pandang kelas-kelas dan objek-objek yang ditemui dalam ruang lingkup permasalahan. Sedangkan Object oriented design adalah metode untuk mengarahkan komposisi perangkat lunak yang didasarkan pada manipulasi objek-objek sistem atau subsistem (Suhendar dan Gunadi, 2002). OOAD adalah suatu metode pengembangan sistem yang lebih ditekankan pada objek dibanding dengan data atau proses. Ada beberapa ciri khas dari pendekatan ini (Al Fatta, 2007):

1. Object adalah struktur yang mengenkapsulasi atribut dan metode yang beroperasi berdasarkan atribut-atribut. Object adalah abstraksi dari benda nyata dimana data dan proses diletakkan bersama untuk memodelkan struktur dan prilaku dari objek dunia nyata.

2. Object class adalah sekumpulan objek yang berbagi struktur yang sama dan prilaku yang sama.

\section{B.3. Unifield Modelling Language (UML)}

Unified Modeling Language (UML) adalah sebuah standar bahasa yang biasa digunakan di dunia industri untuk mengartikan requirement, membuat analisis dan perancangan, serta menggambarkan arsitektur dalam pemrograman berorientasi objek (Rosa dan Shalahuddin, 2013). UML tidak menentukan metode untuk sistem-sistem pengembang, hanya catatan yang saat ini telah diterima luas sebagai standar untuk pemodelan objek (Whitten dkk., 2004). Pada saat menggunakan UML untuk membangun perangkat lunak, pemodelan bisnis dapat membantu untuk memahami kontek sistem yang akan dibangun. Kedengarannya sepele, tetapi mempunyai konsekuensi yang serius pada kesuksesan atau kegagalan dalam merancang perangkat lunak. Jika gagal memahami proses bisnis, maka akan didapatkan penafsiran yang salah tentang apa yang perangkat lunak perlukan Sholiq (2006)

\section{B.4. Database}

Menurut Kadir (2003), basis data (database) adalah data yang saling terkumpul dan terorganisi yang berhubungan satu sama lain dimana dapat menghasilkan kegiatan mendapapatkan informasi lebih mudah. Tujuan dari basis data ialah agar masa didalam sistem yang menggunakan penghampiran berdasar file dapat diatasi. Menurut Fathansyah (1999), basis data terdiri dari dua kata, yaitu basis dan data. Basis bermakna sebagai gudang Sedangkan data ialah reprentasi bukti dunia nyata yang mewakili suatu objek seperti manusia, hewan barang, konsep, peristiwa dan sebagainya. Kemudian data tadi direkam dalam bentuk angka, huruf, teks, gambar, simbol, bunyi, ataupun kombinasinya.

\section{METODOLOGI PENELITIAN}

Pendekatan pengembangan sistem yang digunakan pada penelitian ini adalah object oriented 
analysis and design (OOAD). Ada empat buah diagram unified modeling language (UML) yang digunakan, yaitu: (1) usecase diagram; (2) sequence diagram; (3) class diagram; dan (4) activity diagram.

\section{C.1. Perencanaan}

Langkah awal untuk mengembangkan sebuah sistem dimulai dengan adanya satu kebijakan dan perencanaan yang baik. Tanpa adanya perencanaan yang baik, pengembangan sistem tidak akan berjalan sesuai dengan yang diharapkan. Tahap perencanaan merupakan pedoman untuk melakukan satu pengembangan sistem. Berikut adalah langkah perencanaan yang dilakukan:

\section{Menentukan topik}

Langkah awal yang diambil ialah menentukan topik permasalah pada tugas akhir ini. Setelah melakukan observasi maka peneliti menentukan topik yang akan diangkat yaitu membangun sistem informasi Monitoring perjalanan kapal.

\section{Menentukan objek penelitian}

Ketika tahap menentukan topik dilakukan dan mendapatkan sebuah topik, maka PT. Pelayaran Laut Seraya dijadikan bahan observasi pada Tugas Akhir ini.

\section{Perumusan masalah}

Pada langkah ini peneliti merumuskan masalah masalah yang dikaji dalam Tugas Akhir ini.

\section{Penentuan judul}

Berdasarkan permasalahan yang telah ditentukaan, maka peneliti menentukan judul tugas akhir yang akan diteliti yaitu sistem informasi Monitoring perjalanan kapal.

\section{Penentuan tujuan}

Langkah ini bertujuan agal hal-hal yang menjadi dari penelitian Tugas Akhir ini menjadi lebih jelas.

\section{Rumusan masalah}

Rumusan masalah dilakukan untuk menentukan masalah-masalah yang akan diselesaikan.

\section{ANALISA DAN PERANCANGAN \\ D.1. Analisa Sistem yang Sedang Berjalan}

Ada 5 uraian analisisa sistem yang sedang berjalan pada PT. Pelayaran Laut Seraya:

1) Bagian operasional menelpon setiap kapten kapal yang berjumlah 14 orang atau sebaliknya untuk melaporkan kondisi yang terjadi di lapangan pada saat itu.

2) Setelah mengetahui kondisi yang terjadi dilapangan bagian operasional memasukkan data hasil monitoring ke dalam Microsoft Excel.
3) Setelah semua laporan monitoring dimasukkan kedalam Microsoft Excel bagian operasional mencetak laporan monitoring untuk dilaporkan kepada direktur utama.

4) Setelah laporan monitoring tadi di ketahui oleh direktur utama bagian operasional melakukan scan hasil monitoring untuk dikirim melalui email kepada pemilik saham dan juga rekan kerja.

5) Setelah itu bagian operasional melaporkan laporan monitoring tadi kepada bagian pengarsipan untuk di arsipkan dan dilaporkan ke bagian keuangan sebagai pedoman bagian keuangan untuk menentukan laba rugi perusahaan.

\section{D.2. Analisa Sistem Usulan}

Tahapan berikutnya ialah tahap analisa sistem yang diusulkan, ada 5 analisa sistem yang diusulkan, yaitu:

1) Bagian operasional menelpon setiap kapten kapal yang berjumlah 14 orang atau sebaliknya untuk melaporkan kondisi yang terjadi di lapangan pada saat itu.

2) Setelah mengetahui kondisi yang terjadi dilapangan bagian operasional memasukkan data hasil monitoring ke dalam sistem yang akan dibangun.

3) Laporan monitoring yang dimasukkan kedalam sistem dapat dilihat oleh semua bagian, operasional, direktur utama, pengarsipan, keuangan.

4) Setelah laporan monitoring di masukkan ke dalam sistem oleh bagian operasional maka direktur utama dapat melihat dan mengkonfirmasi bahwa laporan sudah di ketahui oleh direktur utama, dan bagian pengarsipan dapat melihat serta mencetak laporan yang sudah di ketahui oleh direktur utama tadi.

5) Laporan hasil akhir berupa hardcopy yang dapat digunakan untuk melaporkan kegiatan kapal kepada dinas terkait.

\section{D.2.1. Arsitektur Sistem}

Arsitektur sistem yang digunakan dalam membangun sistem informasi monitoring perjalanan kapal ini merupakan interaksi antara komponen yang terdapat didalam sistem tersebut. Arsitektur sistem ditunjukan pada Gambar 2. 


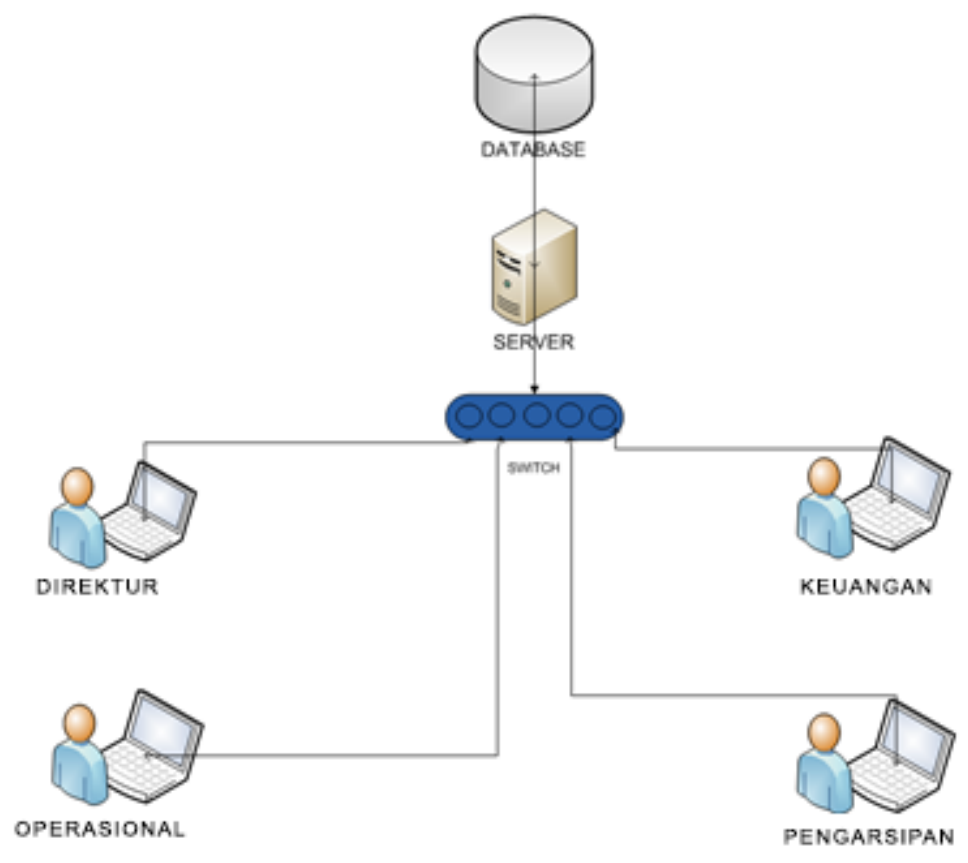

Gambar 2. Arsitektur sistem

\section{D.2.2. Kebutuhan Fungsional Sistem}

Sistem yang dirancang memiliki empat buah aktor, yaitu administrator, pimpinan/direktur utama, keuangan, pengarsipan.

Gambar 3 merupakan aliran data masingmasing usecase yang ada pada usecase diagram digambarkan menggunakan sequence diagram. Gambar 4 dan Gambar 5. Gambar 6 merupakan rancangan class diagram.

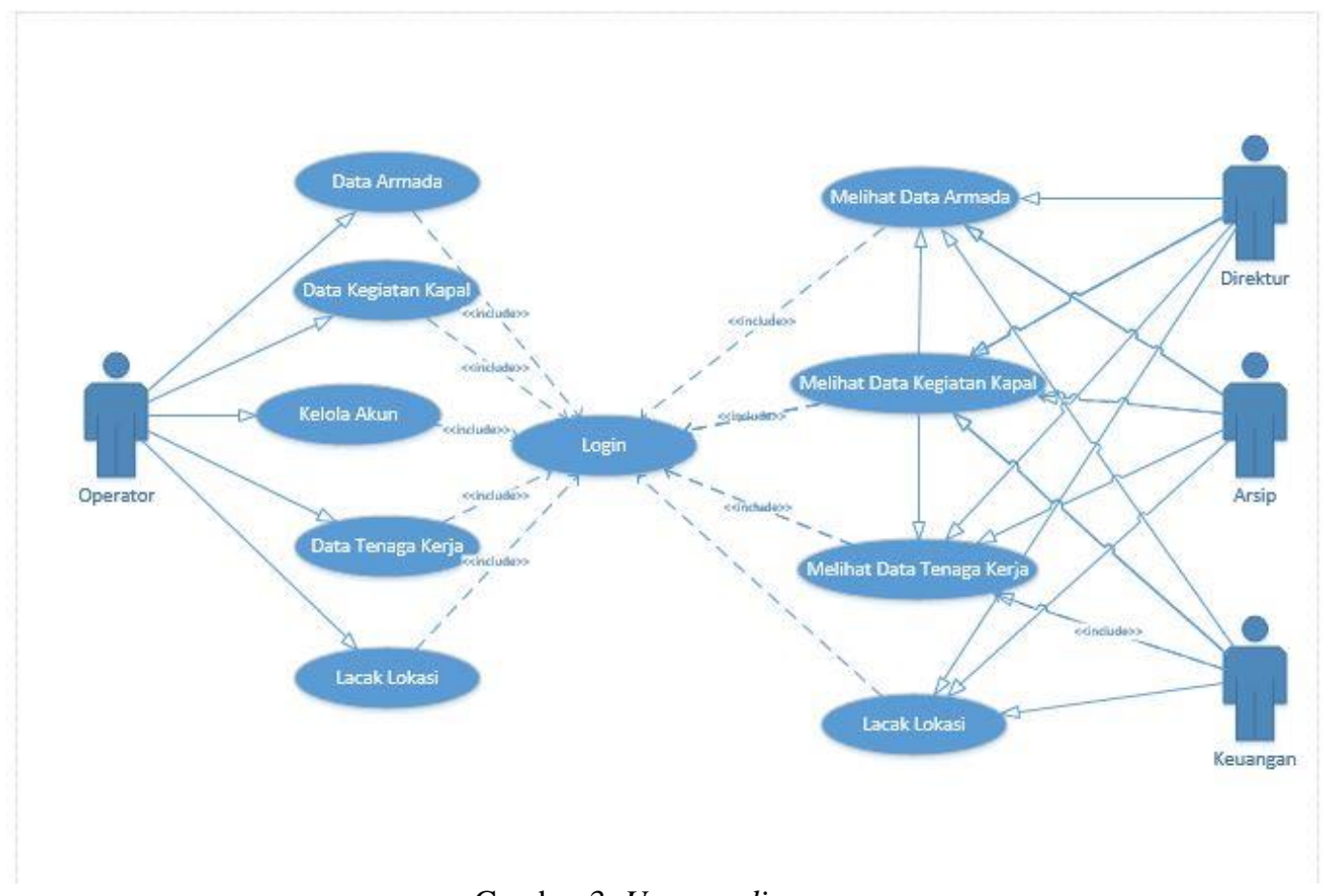

Gambar 3. Usecase diagram 
Jurnal Ilmiah Rekayasa dan Manajemen Sistem Informasi, Vol. 5, No. 2, Agustus 2019, Hal. 171-183 e-ISSN 2502-8995 p-ISSN 2460-8181

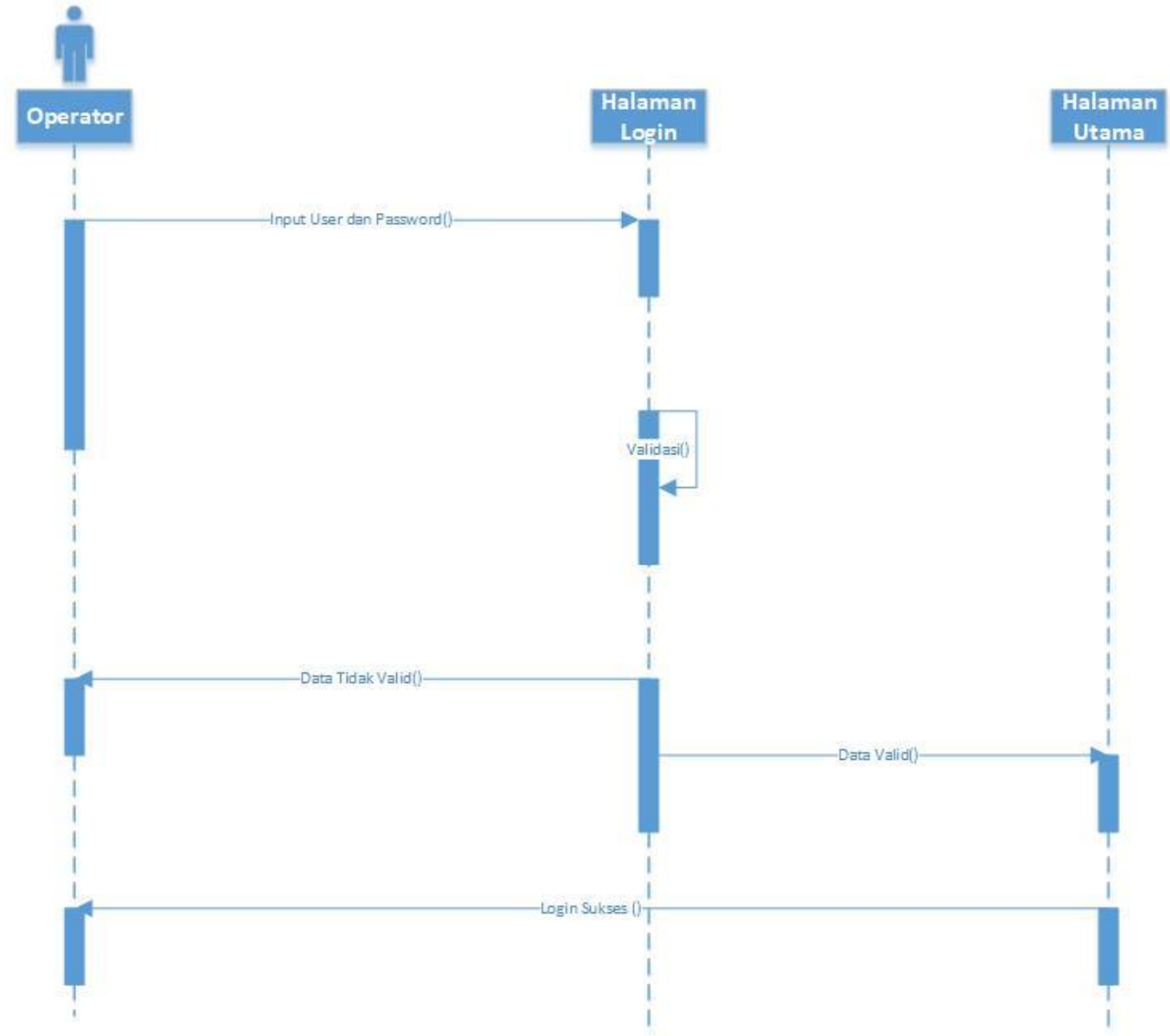

Gambar 4. Sequence diagram operator login

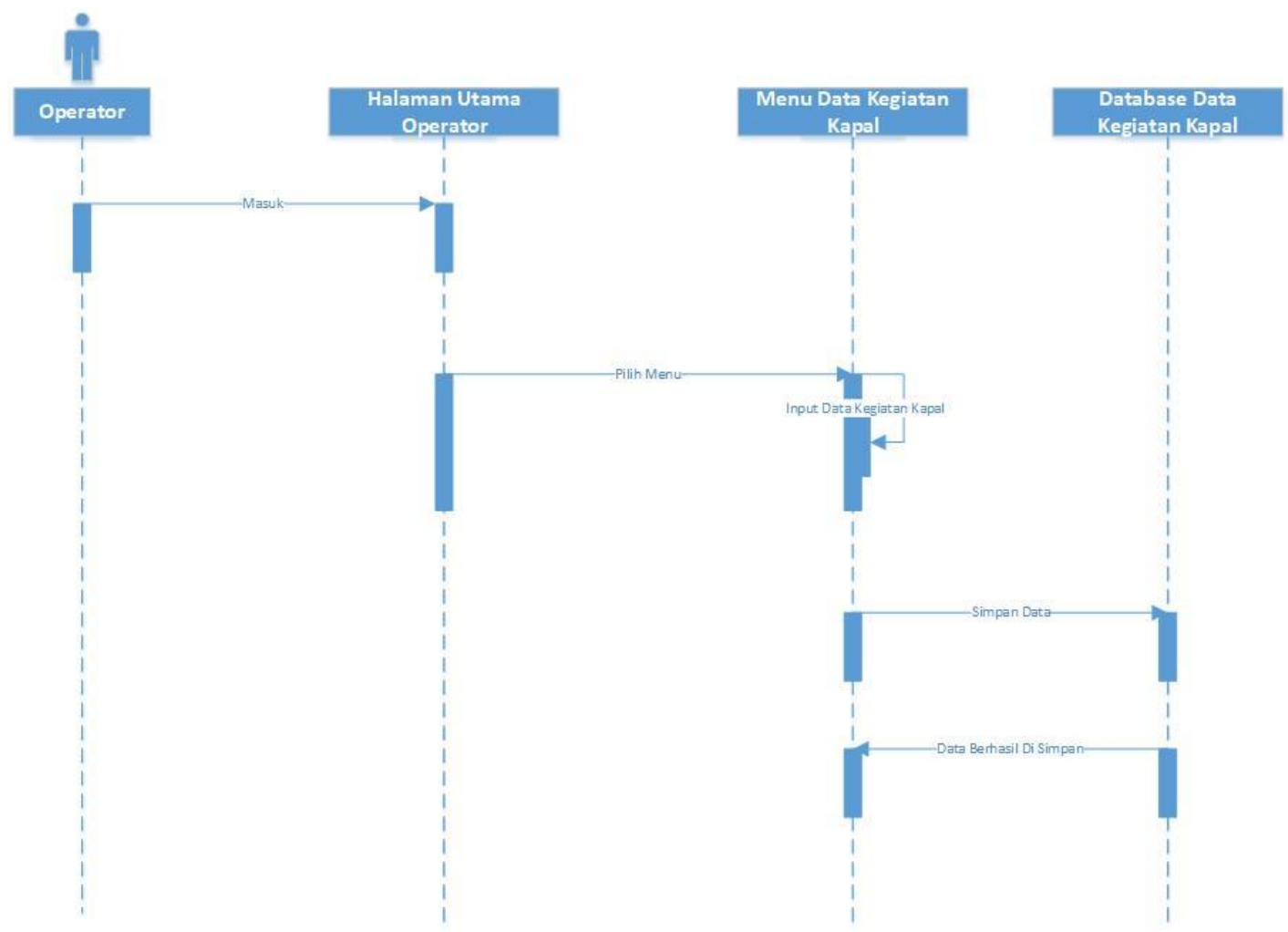

Gambar 5. Sequence diagram kegiatan kapal 
Jurnal Ilmiah Rekayasa dan Manajemen Sistem Informasi, Vol. 5, No. 2, Agustus 2019, Hal. 171-183 e-ISSN 2502-8995 p-ISSN 2460-8181

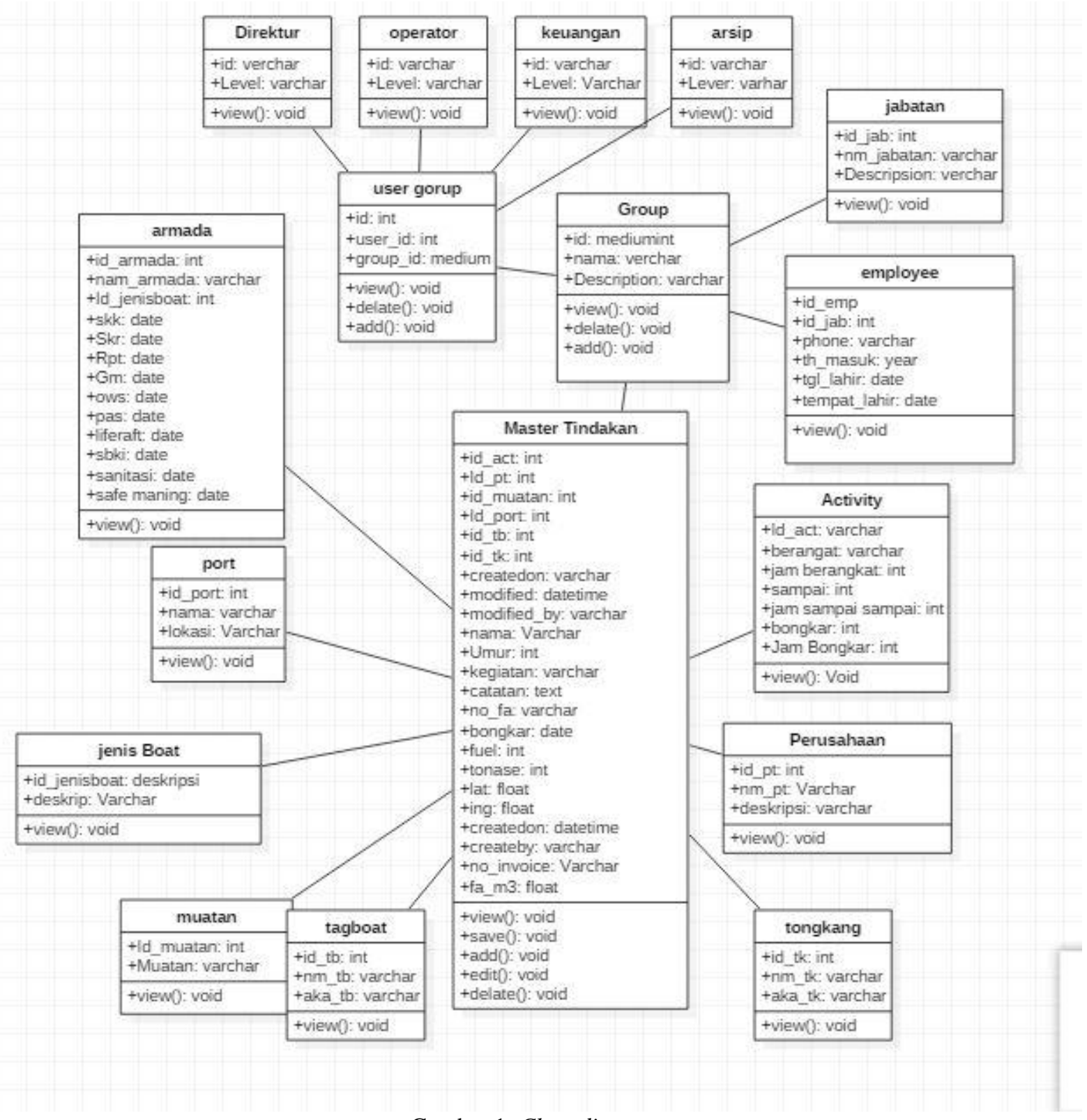

Gambar 1. Class diagram 


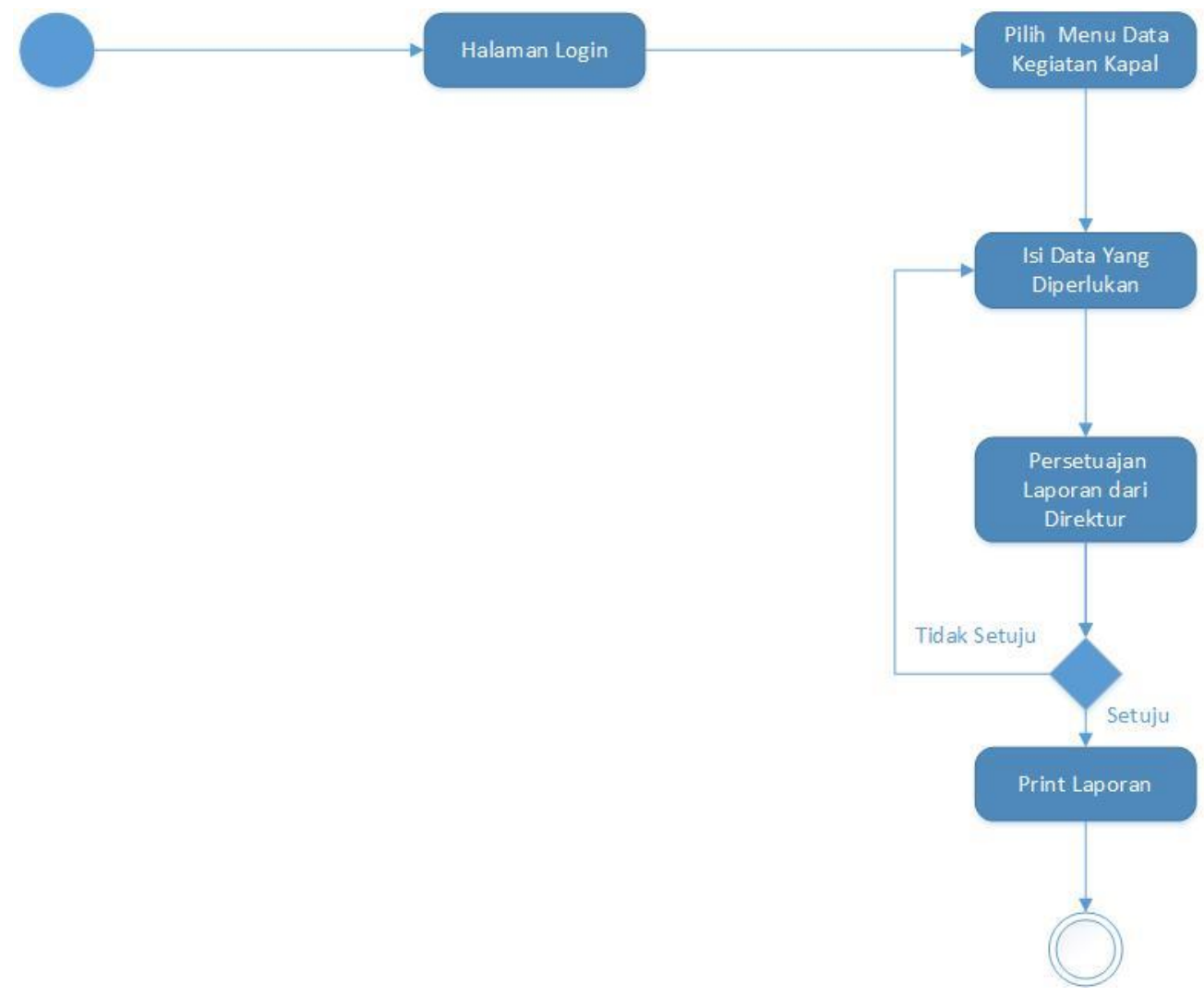

Gambar 2. Activity diagram kegiatan kapal

\section{E. HASIL IMPLEMANTASI DAN PENGUJIAN}

\section{E.1. Hasil Implementasi Sistem} Administrator

Pada sistem administrator terdapat 21 buah halaman antarmuka, yaitu: (1) halaman login; (2) halaman utama sistem; (3) halaman pengelolaaan Data Kegiatan Kapal (DKK); (4) halaman tambah DKK; (5) halaman edit DKK; (6) halaman view DKK; (7) halaman cetak DKK; (8) halaman Data Armada (DA); (9) halaman tambah DA; (10) halaman edit DA; (11) halaman view DA; (12) halaman Data Tenaga Kerja (DTK); (13) halaman tambah DTK; (14) halaman edit DTK; (15) halaman view DTK; (16) halaman lacak lokasi; (17) halaman Kelola Akun (KA); (18) halaman tambah KA; (19) halaman edit KA; (20) halaman profil (21) halaman edit profil.

Gambar 7 merupakan awal sistem informasi monitoring perjalanan kapal sebelum masuk kedalam sistem. Untuk dapat mengakses sistem pengguna harus memasukkan username dan password, jika berhasil akan muncul halaman beranda, dan jika username dan password tidak valid maka akan muncul incorrect login dan akan kembali ke halaman login.

Gambar 8 halaman beranda admin/operasional merupakan halaman beranda dari admin setelah melakukan login. Pada halaman beranda admin/operasional terdapat beberapa menu untuk memonitoring kegiatan kapal.

Gambar 9 merupakan tampilan antarmuka data kegiatan kapal yang berfungsi untuk menambah, merubah, mencari, mencetak, serta menghapus kegiatan kapal pada PT. Perusahaan Laut Seraya.

Gambar 10 merupakan tampilan antarmuka data armada yang berfungsi untuk menambah, merubah, mencari,serta menghapus data armada yang dimilikai PT. Perusahaan Laut Seraya.

Gambar 11 merupakan tampilan antarmuka data tenaga kerja yang berfungsi untuk menambah, merubah, mencari, serta menghapus data tenaga kerja pada PT. Perusahaan Laut Seraya.

Gambar 12 merupakan tampilan antarmuka lacak lokasi yang berfungsi untuk melacak lokasi armada yang dimiliki PT. Perusahaan Laut Serya. Pada menu lacak lokasi data lokasi didapat melalui data yang dikirim oleh perusahaan penyedia jasa tracking kapal yang bernama Polestar Global melalui email yang kemudian data tersebut diinputkan ke dalam sistem yang telah dibuat.

Gambar 13 merupakan tampilan antarmuka kelola akun yang berfungsi untuk menambah user yang dapat menggunakan sistem informasi monitoring pada PT. Perusahaan Laut Seraya.

Gambar 14 merupakan tampilan antarmuka laporan harian kapal yang dimasukkan setiap hari. 
Jurnal Ilmiah Rekayasa dan Manajemen Sistem Informasi, Vol. 5, No. 2, Agustus 2019, Hal. 171-183 e-ISSN 2502-8995 p-ISSN 2460-8181

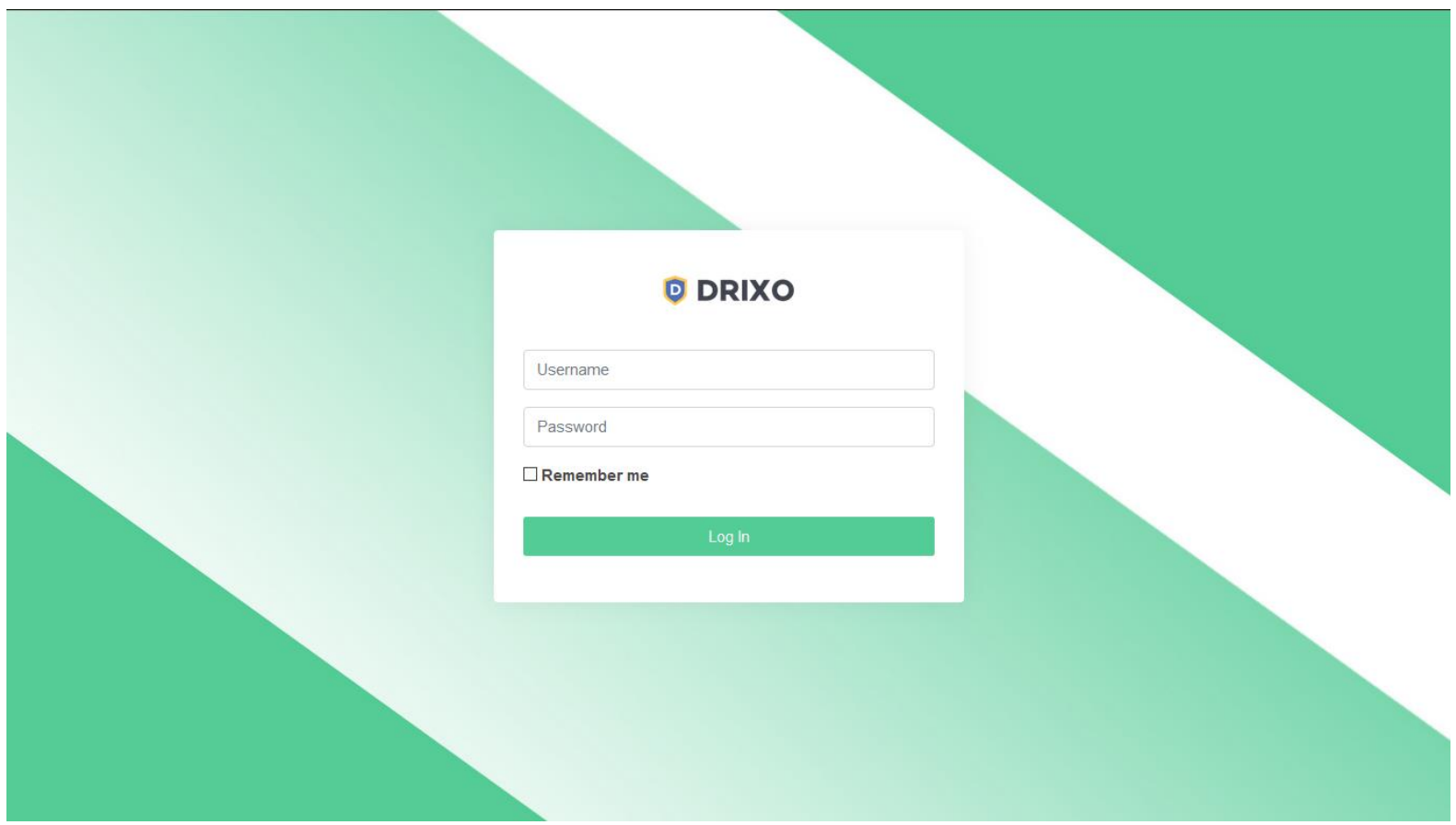

Gambar 7. Halaman antarmuka login

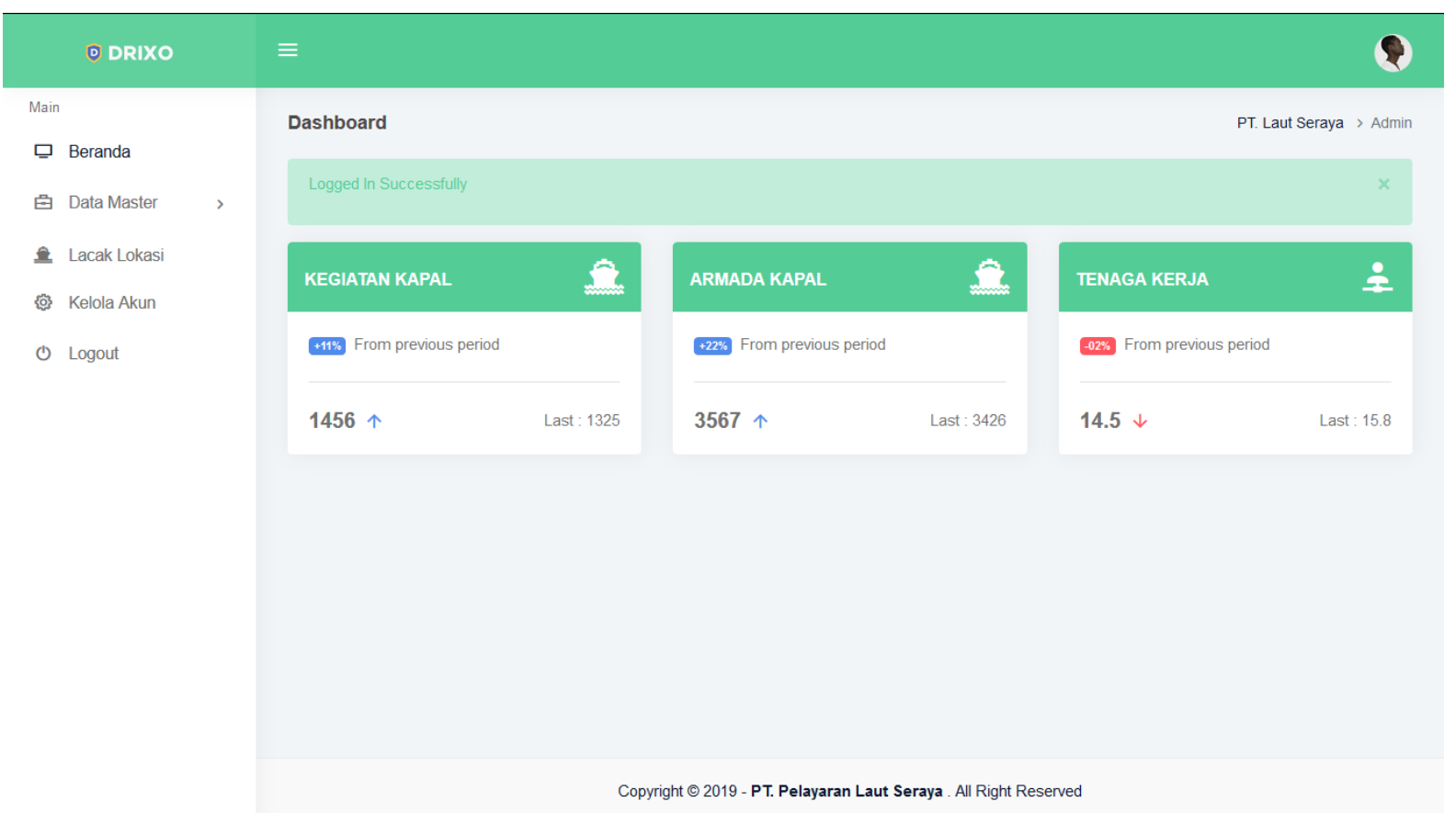

Gambar 8. Halaman antarmuka beranda operasional 
Jurnal Ilmiah Rekayasa dan Manajemen Sistem Informasi, Vol. 5, No. 2, Agustus 2019, Hal. 171-183 e-ISSN 2502-8995 p-ISSN 2460-8181

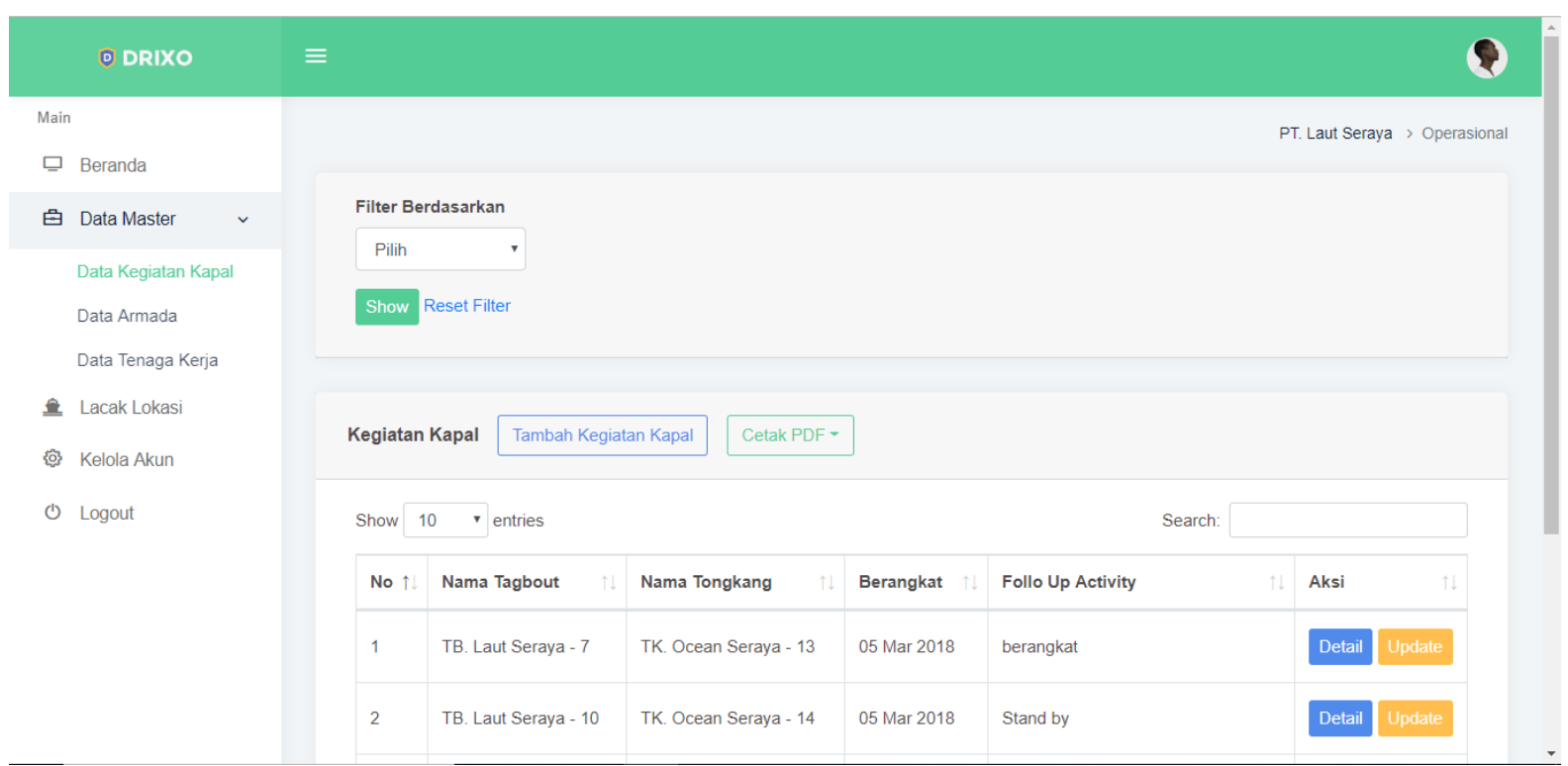

Gambar 9. Halaman antarmuka data kegiatan kapal

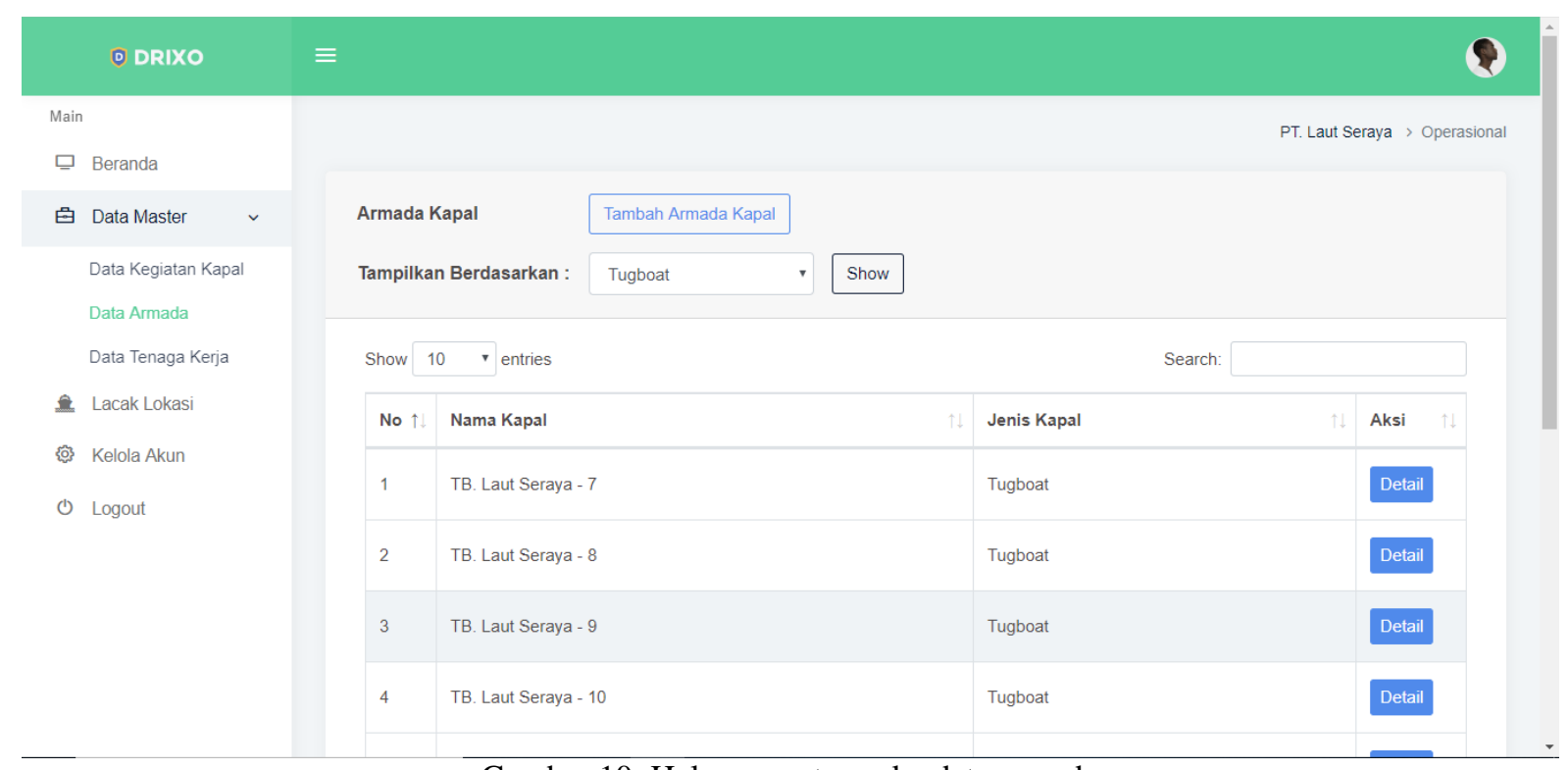

Gambar 10. Halaman antarmuka data armada 
Jurnal Ilmiah Rekayasa dan Manajemen Sistem Informasi, Vol. 5, No. 2, Agustus 2019, Hal. 171-183 e-ISSN 2502-8995 p-ISSN 2460-8181

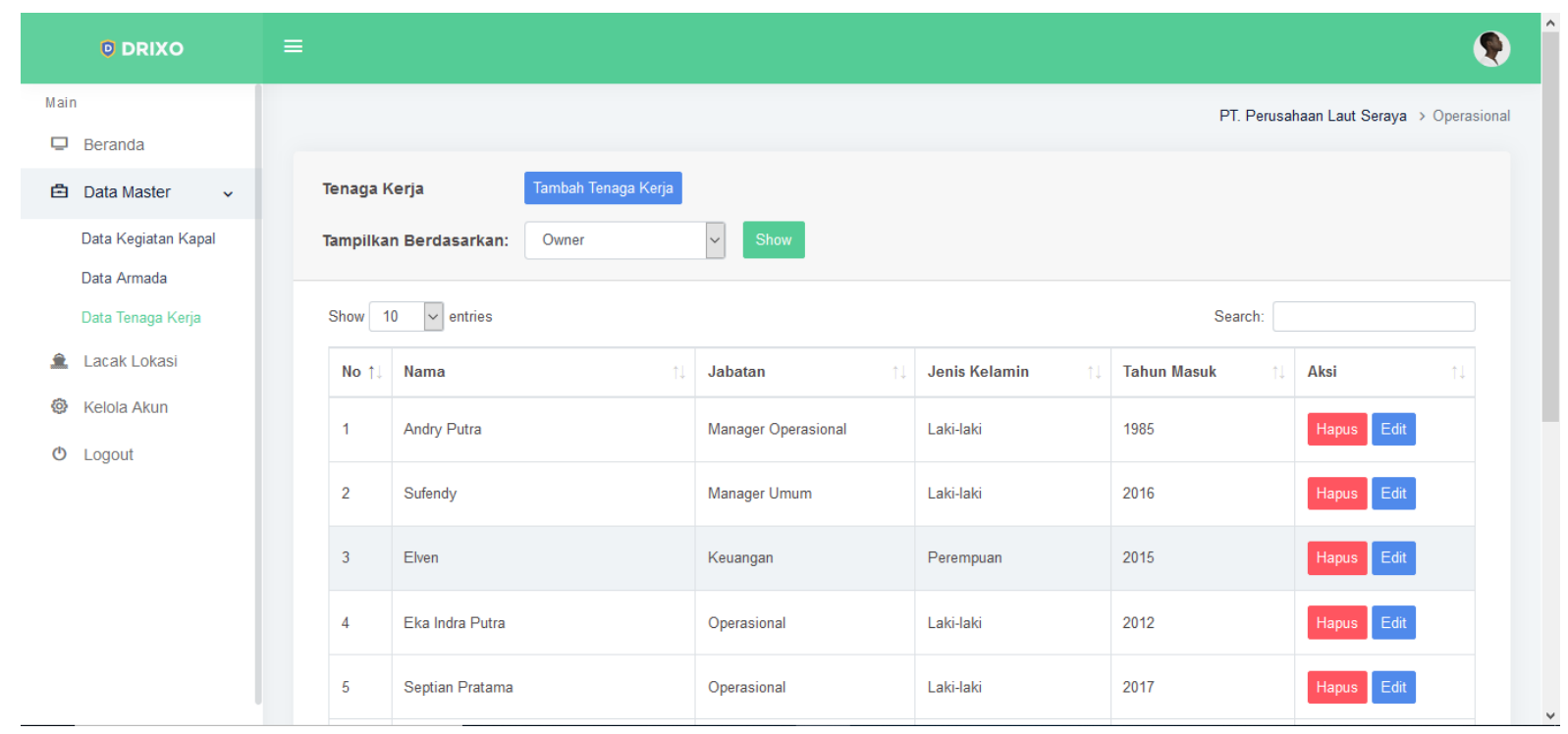

Gambar 11. Halaman antarmuka data tenaga kerja

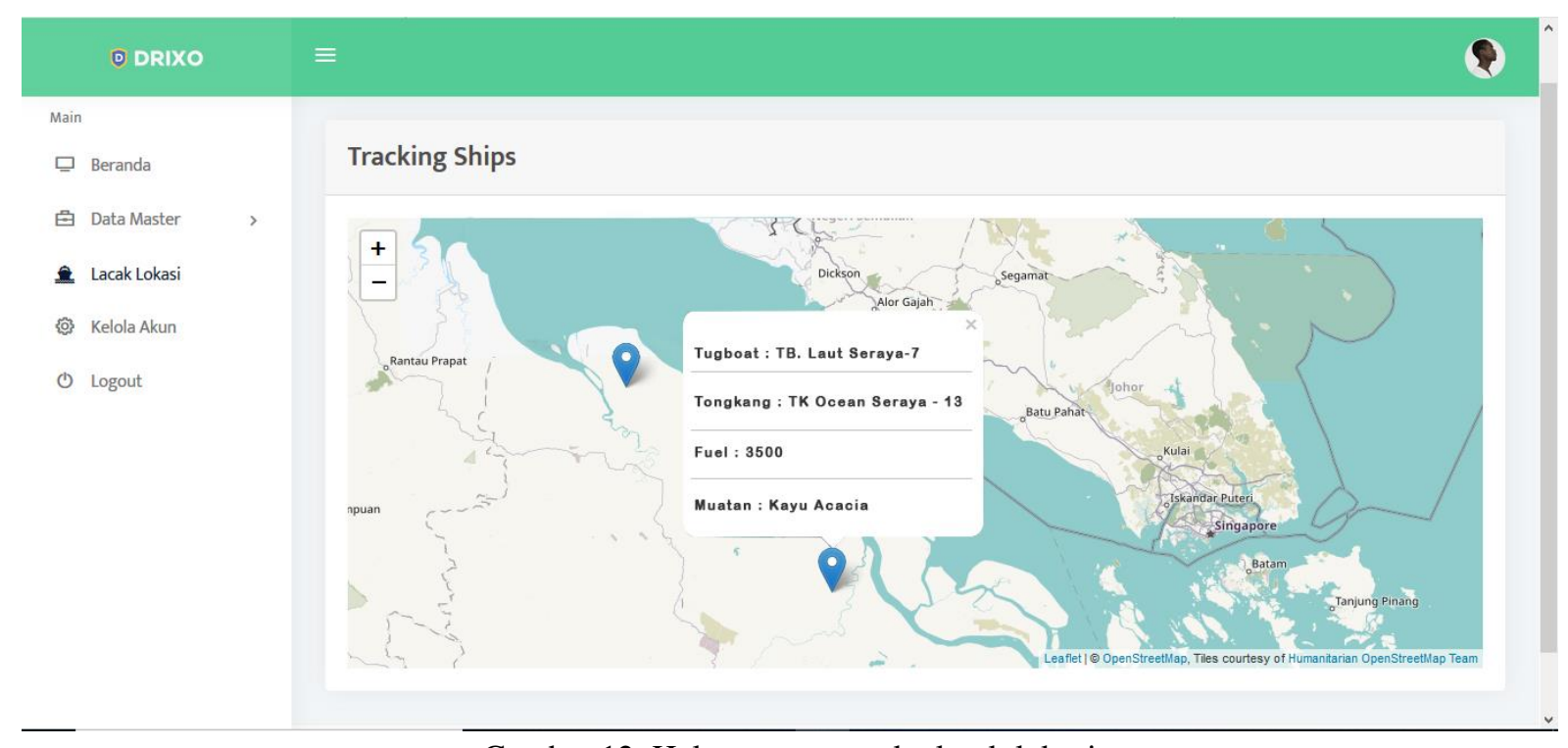

Gambar 12. Halaman antarmuka lacak lokasi 


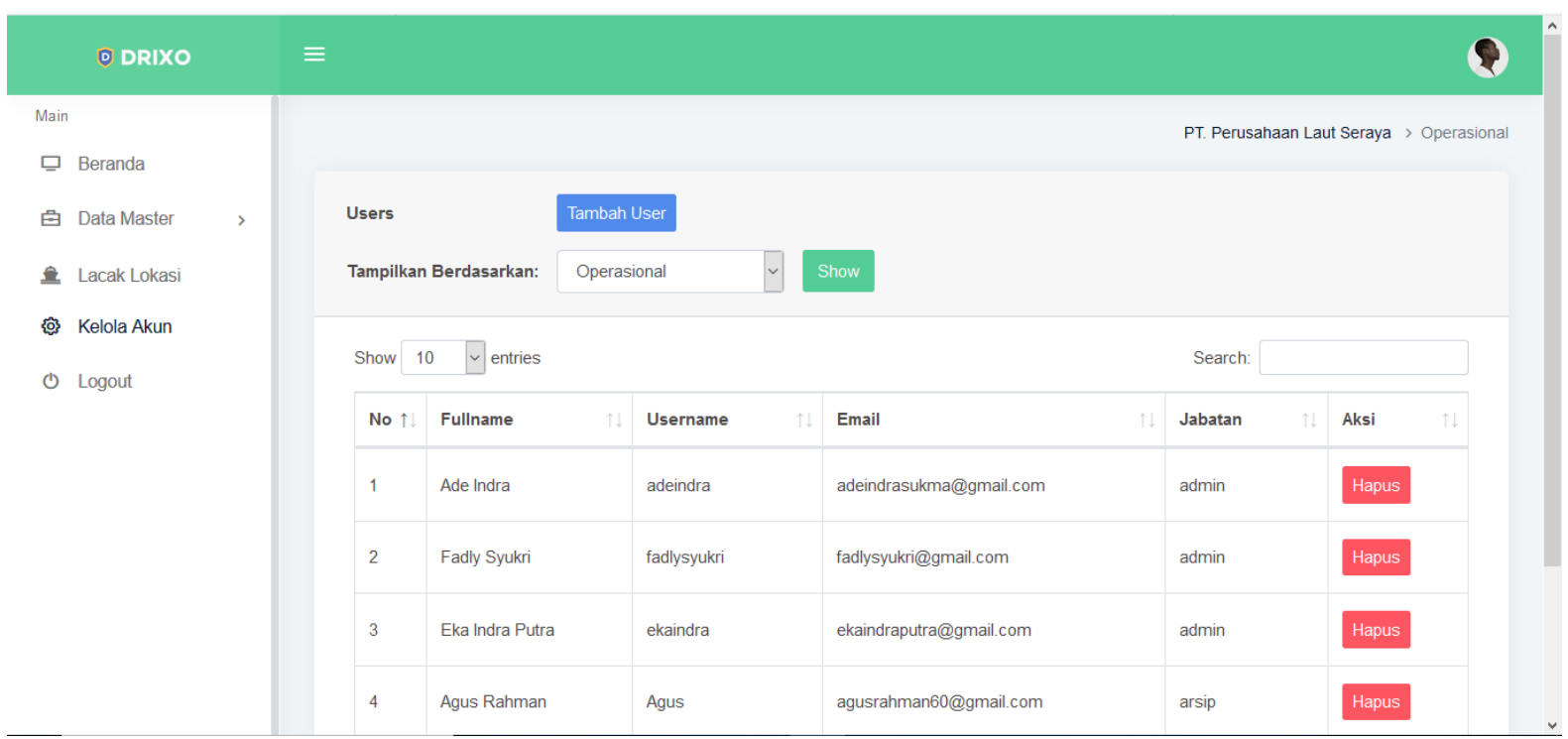

Gambar 13. Halaman antarmuka kelola akun

Hari : Monday

Tanggal : 08 April 2019

Waktu : 17:02 WIB

Daily Monitoring Operation

\begin{tabular}{|c|c|c|c|c|c|}
\hline No. & Areal & Name Ship & Name Barge & Fuel & Follow Up Activity \\
\hline 1 & Futong & TB. LS 7 & TK. OC 13 & 0 & berangkat \\
\hline 2 & Futong & TB. LS 10 & TK. OC 14 & 0 & Stand by \\
\hline 3 & Futong & TB. Multi Seraya & TK. OC 8 & 0 & Stand by proses muat masih antri \\
\hline 4 & Futong & TB. LS 8 & TK. OC 9 & 0 & Sedang Proses Muat \\
\hline
\end{tabular}

1. TB. LS 7: Permintaan Pelampung Lifeboy

2. -

3. Multi Seraya: Permintaan radio HT, Tali toing

4. TB. LS 8: Permintaan Tali Toing, Pelampung Lifeboy, Oli 1 Drum, Air Batrai 2 Kotak, Batrai Radio 1.

Prepared by,

ekaindra

Gambar 14. Laporan harian

\section{E.2. Hasil Pengujian}

Setelah melakukan pengujian pada lima orang responden menggunkan metode pengujian blackbox. Modul sistem yang digunakan dalam pengujian ini adalah 33 modul sistem. Penilaian keberhasilan persentasi dinilai kepada setiap responden, maka jenis device yang digunakan untuk pengujian dan hasil bisa dilihat pada Tabel 1 dan Tabel 2.

Setelah kuisioner diatas diberikan kepada responden, kemudian data kuesioner tersebut diolah untuk mendapatkan hasil penilaian user acceptance test. Penilaian dilakukan dengan menggunakan skala likert dengan penilaian skor $4=$ Poin A, skor $3=$ Poin B, skor 2 = Poin C dan skor 1 = Poin D. Jumlah responden yang akan melakukan pengisian kuisioner tersebut berjumlah 4 (empat) orang, yang mana sesuai pada wawancara dengan Bapak Eka Indra Putra, SE (2017) tim yang akan dibentuk untuk pengujian sistem informasi monitoring tersebut berjumlah 4 orang. Adapun hasil penilaian user acceptance test tersebut terlihat pada Tabel 2. 
Tabel 1. Hasil uji black box

\begin{tabular}{|c|c|c|c|}
\hline \multicolumn{4}{|c|}{$\begin{array}{c}\text { Hasil Pengujian Blackbox } \\
\text { Pengujian Blackbox Sistem Informasi Monitoring }\end{array}$} \\
\hline Nama & Berhasil & Gagal & Tingkat Keberhasilan \\
\hline Responden 1 & 33 & & $100 \%$ \\
\hline Responden 2 & 33 & & $100 \%$ \\
\hline Responden 3 & 33 & & $100 \%$ \\
\hline Responden 4 & 33 & & $100 \%$ \\
\hline Responden 5 & 33 & & $100 \%$ \\
\hline Rata-rata & & & $100 \%$ \\
\hline
\end{tabular}

\section{Tabel 2. Hasil UAT}

\begin{tabular}{|c|c|c|c|c|c|c|c|}
\hline \multirow{2}{*}{ No } & \multirow{2}{*}{ Pertanyaan } & \multicolumn{4}{|c|}{ Jawaban } & \multirow{2}{*}{ Jumlah } & \multirow{2}{*}{$\begin{array}{c}\text { Tingkat } \\
\text { Penerimaan }\end{array}$} \\
\hline & & Ax4 & $\mathbf{B \times 3}$ & Cx2 & Dx1 & & \\
\hline 1 & Pertanyaan 1 & 8 & 9 & - & - & 17 & $85 \%$ \\
\hline 2 & Pertanyaan 2 & 8 & 9 & - & - & 17 & $85 \%$ \\
\hline 3 & Pertanyaan 3 & 16 & 3 & - & - & 19 & $95 \%$ \\
\hline 4 & Pertanyaan 4 & 12 & 6 & - & - & 18 & $90 \%$ \\
\hline 5 & Pertanyaan 5 & 4 & 12 & - & - & 16 & $80 \%$ \\
\hline 6 & Pertanyaan 6 & 8 & 9 & - & - & 17 & $85 \%$ \\
\hline 7 & Pertanyaan 7 & - & 15 & - & - & 15 & $75 \%$ \\
\hline 8 & Pertanyaan 8 & 8 & 12 & - & - & 16 & $80 \%$ \\
\hline \multicolumn{2}{|c|}{ Rata-rata } & & & & & & $84,375 \%$ \\
\hline
\end{tabular}

\section{F. KESIMPULAN}

Kesimpulan dari tugas akhir ini adalah: (1) Sistem informasi monitoring perjalanan kapal pada PT. Pelayaran Laut Seraya sudah berhasil dibangun; (2) Sistem ini berguna bagi pegawai dalam melakukan kegiatan monitoring perjalanan kapal; (3) Dengan adanya sistem dapat memudahkan kinerja pegawai dalam menata dokumen secara elektronik dan restruktur; (4) Dengan adanya sistem dapat membantu dalam pembuatan laporan maupun pencarian dokumen sesuai periode yang diinginkan; (5) berdasarkan hasil uji blackbox menggunakan 5 buah Device dengan spesifikasi yang berbeda, kebutuhan fungsional sistem informasi Monitoring sudah berjalan dengan baik dengan tingkat keberhasilan 100\%; (6)berdasarkan hasil user acceptance test pada 5 orang responden, sistem ini memiliki tingkat penerimaan yang baik, yaitu dengan tingkat penerimaan $84,375 \%$.

\section{REFERENSI}

[1] Al Fatta, H. (2007). Analisis dan perancangan sistem informasi untuk keunggulan bersaing perusahaan dan organisasi modern. Penerbit Andi.

[2] Aprisa, A., dan Monalisa, S. (2015). Rancang bangun sistem informasi monitoring perkembangan proyek berbasis web (studi kasus: Pt. inti pratama semesta). Jurnal Ilmiah Rekayasa dan Manajemen Sistem Informasi, 1(1), 49-54.

[3] Azis, I. M. F., dan Kom, M. (2005). Object oriented programming php 5. Elex Media Komputindo.

[4] Fathansyah, I. (1999). Basis data. Informatika, Bandung.

[5] Ghony, M. D., dan Almanshur, F. (2012). Metodologi penelitian kualitatif. Jogjakarta: Ar-Ruzz Media.

[6] Haviluddin, H. (2016). Memahami penggunaan uml (unified modelling language). Informatika Mulawarman: Jurnal Ilmiah Ilmu Komputer, 6(1), 1-15.

[7] Herliana, A., dan Rasyid, P. M. (2016). Sistem informasi monitoring pengembangan software pada tahap development berbasis web. Jurnal Informatika, 3(1).

[8] Kadir, A. (2003). Pengenalan sistem informasi. Andi.

[9] Kristanto, A. (2018). Perancangan sistem informasi dan aplikasinya.

[10] Lany Mayangsari, Y. E. (2014). Sistem informasi monitoring kuliah online pada amik wahana mandiri tangerang selatan berbasis web. Konferensi Nasional Sistem Informasi.

[11] Mudjahidin,M.,danPutra,N.D.P. （2012). Rancang bangun sistem informasi monitoring perkembangan proyek berbasis web. Jurnal Teknik Industri, 11(1), 75-83.

[12] Nawawi, H. (1993). Metode penelitian bidang sosial. Gadjah Mada University Press.

[13] Nugroho,A. (2005). Analisis dan perancangan sistem informasi dengan metodologi berorientasi objek. Bandung: Informatika.

[14] Ragil, W. (2010). Pedoman sosialisasi prosedur operasi standar. Jakarta: Mitra Wacana Media.

[15] Ramadhan, M. R., Nugroho, L. E., dan Sulistyo, S. (2017). Evaluasi sistem informasi monitoring skripsi menggunakan prinsip usability. Prosiding SNST Fakultas Teknik, 1(1).

[16] Risnandar, E., dkk. (2015). Pembuatan aplikasi sistem informasi monitoring kegiatan mahasiswa berbasis web dan android client (Unpublished doctoral dissertation). UNIVERSITAS NEGERI SEMARANG.

[17] Rosa, A. S.,dan Shalahuddin, M. (2013). Rekayasa perangkat lunak terstruktur dan berorientasi objek. Bandung: informatika.

[18] Sholiq, P. S. I. B. O. (2006). dengan uml. Yogyakarta: Graha Ilmu.

[19] Suhendar, A., dan Gunadi, H. (2002). Visual modeling menggunakan uml dan rational rose. Informatika, Bandung.

[20] Sumadyo,M. (2009). Rancang bangun sistem pelaporan pendapatan harian dengan sms gateway dan monitoring hasil berbasis web pada perusahaan pengisian ban nitrogen. PARADIGMA: JURNAL ILMU PENGETAHUAN AGAMA, DAN BUDAYA, 10(2), 212-221.

[21] Whitten, J. L., Bentley, L. D., dan Dittman, K. C. (2004). Metode desain dan analisis sistem. Andi Offset, Yogyakarta. 
Jurnal Ilmiah Rekayasa dan Manajemen Sistem Informasi, Vol. 5, No. 2, Agustus 2019, Hal. 171-183 e-ISSN 2502-8995 p-ISSN 2460-8181 